\title{
Diverse stakeholders create collaborative, multilevel basin governance for groundwater sustainability
}

\author{
Groundwater sustainability agencies recently formed in three large groundwater basins in \\ the Central Valley have developed innovative ways to incorporate farmers' voices and respect \\ local autonomy.
}

by Esther Conrad, Tara Moran, Marcelle E. DuPraw, David Ceppos, Janet Martinez and William Blomquist

\section{Abstract}

The Sustainable Groundwater Management Act (SGMA) is introducing significant changes in the way groundwater is governed for agricultural use. It requires the formation of groundwater sustainability agencies (GSAs) to manage groundwater basins for sustainability with the engagement of all users. That presents opportunities for collaboration, as well as challenges, particularly in basins with large numbers of agricultural water users who have longstanding private pumping rights. The GSA formation process has resulted in the creation of multiple GSAs in many such basins, particularly in the Central Valley. In case studies of three basins, we examine agricultural stakeholders' concerns about SGMA, and how these are being addressed in collaborative approaches to groundwater basin governance. We find that many water districts and private pumpers share a strong interest in maintaining local autonomy, but they have distinct concerns and different options for forming and participating in GSAs. Multilevel collaborative governance structures may help meet SGMA's requirements for broad stakeholder engagement, our studies suggest, while also addressing concerns about autonomy and including agricultural water users in decision-making.

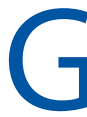
roundwater is a critical resource for Califor-

nia's agricultural sector, accounting for almost $40 \%$ of agricultural water use, and far more in drought years (DWR 2015). Many groundwater basins, particularly in the Central Valley, have experienced significant declines in groundwater levels over the past several decades, and the recent drought heightened concerns over these declines and associated impacts. In 2014, the California Legislature passed the Sustainable Groundwater Management Act (SGMA), introducing for the first time a requirement that local agencies manage groundwater sustainably or face state intervention.

SGMA grants broad authority for groundwater management to locally formed groundwater sustainability agencies (GSAs). Local agencies were given until June 30, 2017, to establish GSAs and until 2020 or 2022

Online: https://doi.org/10.3733/ca.2018a0002

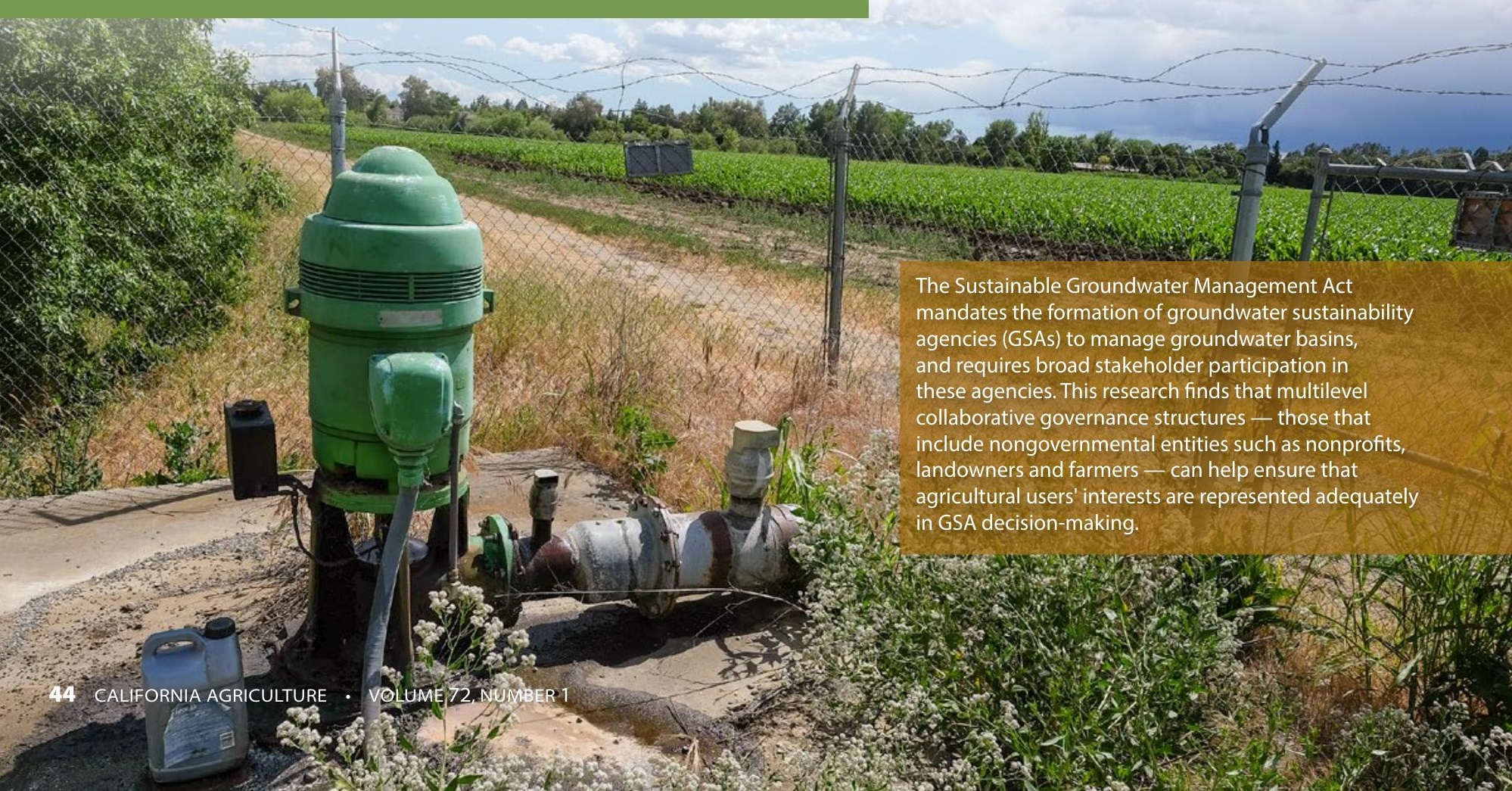


(depending on basin conditions) to adopt groundwater sustainability plans (GSPs), which must consider all "beneficial uses and users" (California Water Code [CWC] \$ 10723.2, California State Legislature, 2014). In groundwater basins where agriculture plays an important role, the number of beneficial users can be large, in some cases including thousands of landowners who have long exercised their overlying pumping rights.

\section{Collaborative governance}

In recent decades, collaborative governance has gained attention as an effective approach to managing common pool resources, including groundwater (Megdal et al. 2017; Ostrom 1990). Collaborative governance has been defined as "the processes and structures of public policy decision-making and management that engage people constructively across the boundaries of public agencies, levels of government, and/or the public, private and civic spheres in order to carry out a public purpose that could not otherwise be accomplished" (Emerson et al. 2012, 2).

Collaborative governance typically involves engaging nongovernmental entities in public policy decisionmaking, which is expected to help develop shared knowledge, trust and buy-in among diverse interests (Ansell and Gash 2008; Innes and Booher 2010). In the context of groundwater governance, such nongovernmental entities would include individual landowners and farmers as well as private or nonprofit organizations representing agricultural interests, among others. While public agencies hold authority deriving from legislative mandates, the influence of nongovernmental entities in a collaborative process is grounded in their authentic representation of key interests and widely accepted values, referred to as discursive legitimacy (Purdy 2012).

Organizing successful collaborations at large scales can be challenging, requiring special efforts to design and track meaningful participation and representation (Ansell and Torfing 2015; DuPraw 2014). Multilevel governance structures featuring collaboration among entities at different scales may be one way to achieve meaningful engagement (Newig and Fritsch 2009). For example, in a river basin, instead of forming a single, basinwide governing body, local agencies and stakeholders work together at smaller scales, but coordinate their efforts across the basin. However, we still have much to learn about how multilevel structures work in practice (Huitema et al. 2009).

In California, collaborative governance in water management has been encouraged in recent decades (Hughes and Pincetl 2014). It has played an important role in the success of certain groundwater adjudications and special act districts in reducing overdraft, but most of these examples are in urban areas or relatively small basins (Blomquist 1992). Across much of the state - including the Central Valley, where basins are large, overdraft is severe, agricultural use is high and overlying rights holders are numerous - collaborative plans to manage groundwater prior to SGMA were voluntary, lacking binding commitments to address groundwater depletion and its impacts (Nelson 2011). By contrast, SGMA requires that in over 125 designated medium- or high-priority basins local management must achieve groundwater sustainability within 20 years of GSP adoption or be subject to state intervention. GSPs must avoid "significant and unreasonable" reductions in groundwater levels and five other "undesirable results."

SGMA effectively requires collaborative governance at the basin scale in the context of developing and implementing GSPs, as distinct from the discretion it allows in GSA formation. If there are multiple GSAs within a groundwater basin, they must either work together to develop a single GSP or sign a coordination agreement ensuring that their multiple GSPs are based on common data and assumptions (CWC $\$ 10727.6$ ) (alternatively, local agencies could collaborate to form a single GSA covering the entire basin, and develop a single GSP). In addition, per statutory language, GSAs must encourage the "active involvement" of all "beneficial users" of groundwater in the development of a GSP (CWC \$ 10727.8).

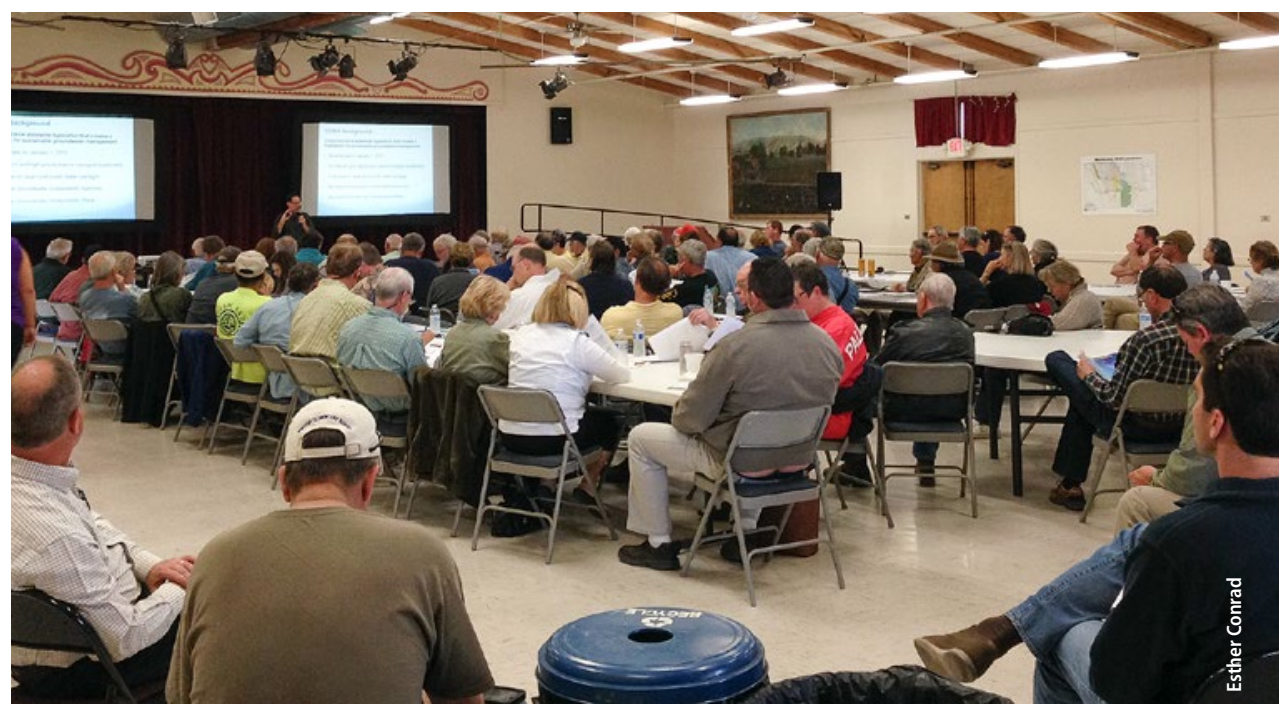

In forming GSAs, on the other hand, SGMA required public involvement but not necessarily collaborative governance. All beneficial users of groundwater had to be consulted in GSA formation (CWC $\$ 10723.2)$, but they were not required to be included in decision-making structures. Public agencies had the authority to form GSAs individually and at any scale. Private pumpers and nonprofit entities such as the Farm Bureau, however, could not. Local agencies could take a collaborative approach to the GSA formation process by including representatives of beneficial users in GSA and basinwide governance structures. Alternatively, agencies could provide beneficial users with opportunities for public input but not a role in
Landowners and other stakeholders participate in a public meeting about the formation of a GSA in Yolo County. The resulting GSA covers the vast majority of the Yolo basin; it has a multilevel governance structure that includes the Yolo County Farm Bureau as a voting member. 


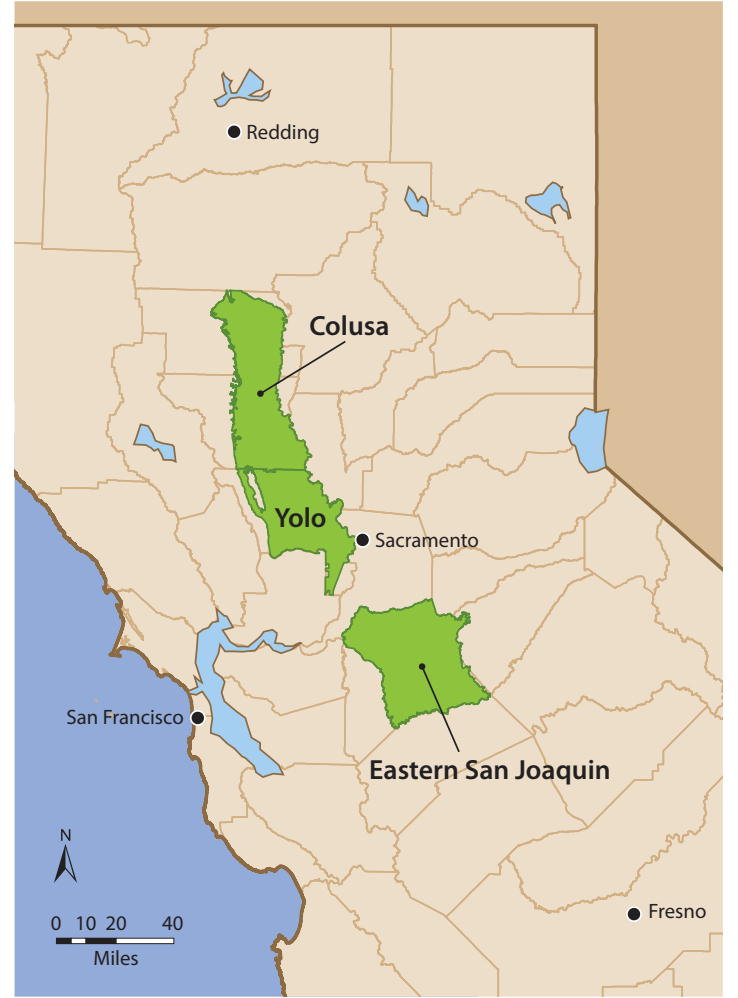

FIG. 1. Case study groundwater basins. decision-making within the GSA or in coordination at the basin scale.

\section{Case studies in three basins}

Agriculture has long been a critical driver of water management in California, and SGMA has significant implications for how agricultural water is managed. To examine how collaborative governance structures are emerging at the basin scale, we undertook case studies of three groundwater basins in California's Central Valley that have followed a collaborative governance approach, and we reviewed data about GSA formation statewide. We address two questions in our case studies: What are agricultural stakeholders' primary concerns in designing groundwater governance under SGMA, and how were those concerns represented in GSA formation. Our aims are to deepen our understanding of how collaborative processes can be structured to manage resources at large scales and to lay the groundwork for future research regarding the effectiveness of those governance arrangements in accommodating diverse stakeholder interests.

Our case studies include the Colusa and Yolo subbasins of the Sacramento Valley groundwater basin and the Eastern San Joaquin subbasin of the San Joaquin Valley basin (fig. 1). Under SGMA, subbasins are treated as groundwater basins, so for simplicity we use the term "basin" for both. These basins were selected because they are relatively large, agriculture plays a significant role in each one, and stakeholders in each of these areas took a collaborative approach to GSA formation at the basin scale.

In all three basins, farmers generally use surface water for irrigation but switch to groundwater when surface supplies are curtailed. Tree crops are important in all three basins, with a particularly significant expansion in Yolo County, where almond acreage has more than doubled since 2010. This expansion is placing additional demand on groundwater, since much of this land was previously unirrigated (Morain 2015). Agricultural production and groundwater dependence are greatest in the Eastern San Joaquin basin, which is critically overdrafted and must complete its GSP by 2020 instead of 2022. Farms are on average smaller in this basin, and more farmland is under irrigation. Table 1 summarizes key features of the three basins.

In all three cases, discussions about a collaborative approach to GSA formation at the basin scale began early and lasted for more than a year. A convening entity played a key role, seeking to include stakeholders across the basin in a group decision-making process (in the Colusa basin, Glenn and Colusa counties conducted

TABLE 1. Overview of case studies in three basins

\begin{tabular}{|c|c|c|c|}
\hline & Yolo & Colusa & Eastern San Joaquin \\
\hline Land area (sq miles) & 788 & 1,099 & 1,202 \\
\hline Population (2010)* & 194,158 & 48,369 & 582,662 \\
\hline No. of countiest & 2 & 2 & 3 \\
\hline Agricultural production value (2015) $\ddagger$ & $\$ 510$ million & \$752 million & $\$ 2.26$ billion \\
\hline Top three crops (by value, 2015)§ & Tomatoes, almonds, grapes & Almonds, rice, walnuts & Almonds, grapes, walnuts \\
\hline Average farm size (acres, 2012)§ & 456 & 545 & 220 \\
\hline Percentage of farmland under irrigation§ & $50 \%$ & $47 \%$ & $62 \%$ \\
\hline Groundwater basin priority $(2014)^{*}$ & High & Medium & High, critically overdrafted \\
\hline Percentage of water use accounted for by groundwater* & $25 \%$ & $10 \%$ & $43 \%$ \\
\hline No. of GSAsף & 2 & 2 & 17 \\
\hline No. of GSA-eligible entities & 33 & 47 & 24 \\
\hline Length of GSA formation process (months) & 19 & $\begin{array}{l}16 \text { (Colusa County); } 13 \text { (Glenn } \\
\text { County) }\end{array}$ & 20 \\
\hline \multicolumn{4}{|c|}{$\begin{array}{l}\text { Sources: } 2016 \text { basin boundaries shapefile (DWR 2015; California Statewide Groundwater Elevation Monitoring Program prioritization data (DWR 2014), California Agricultural Statistics Review 2015-2016 (CDFA 2016), } \\
2012 \text { Census of Agriculture (USDA 2014), and GSA formation meeting notes. }\end{array}$} \\
\hline \multicolumn{4}{|l|}{ * Estimates based on 2003 groundwater basin boundaries. } \\
\hline \multicolumn{4}{|l|}{ † A very small area of the Yolo subbasin falls within neighboring Solano County. } \\
\hline \multicolumn{4}{|c|}{ ‡ Estimates based on county-level data and percentage of county area within each basin. } \\
\hline \multicolumn{4}{|c|}{$\S$ Estimates based on county data (Yolo and San Joaquin counties for Yolo and Eastern San Joaquin basins, and average of Glenn and Colusa counties for Colusa basin). } \\
\hline \multicolumn{4}{|c|}{ I 900 acres of the Yolo basin fall within a reclamation district that formed a separate GSA. This GSA plans to join in a single GSP for the Yolo subbasin. } \\
\hline
\end{tabular}


separate processes but communicated regularly). In the Colusa and Eastern San Joaquin basins, county governments convened these meetings; in the Yolo basin, a nonprofit water association and the Yolo County Farm Bureau led the process. Professional facilitation services were used in all three basins, supported by funding from the California Department of Water Resources (DWR).

Although not representative of all groundwater basins in California, these cases offer insight into the interests of agricultural communities under SGMA, and how these interests have influenced GSA governance structures. Data was gathered from governance documents and meeting notes, as well as from observations of GSA formation meetings during 2016 and 2017, as described in the online technical appendix. In addition, two co-authors served as facilitators for GSA formation in the Yolo and Colusa basins and contributed their knowledge of stakeholder concerns and decisions there.

\section{GSA formation study}

SGMA allows local public agencies with water supply, water management or land use responsibilities to form GSAs. They may do so as single agencies, or join with other local agencies to form a multi-agency GSA through a joint powers agreement (JPA) or memorandum of agreement (MOA). Each proposed GSA was required to send a notice to DWR, indicating its boundaries, the local agencies involved and a description of how it would engage 10 types of beneficial users of groundwater (CWC $\$ 10723.2$, and listed in the technical appendix).

We reviewed GSA formation notices submitted to DWR via its online SGMA portal as of June 30, 2017 (agencies could still revise or submit new notices after that date). We compiled data regarding GSA type (single or multi-agency), beneficial users identified and agricultural interests in GSA governance. We also recorded the number of GSAs declared in each high- and medium-priority basin and evaluated basin coverage by GSAs. The technical appendix provides additional detail on methods.

\section{Agriculture represented in most GSAs}

A diverse array of interests is present within most GSAs in California. Our analysis of GSA formation notices indicates that at least five of the 10 SGMA-identified beneficial users are present in over $80 \%$ of all GSAs. Agricultural interests are present in nearly all GSAs; $87 \%$ of GSAs reported the presence of overlying rights for agricultural use.

Beneficial users have been represented in the GSA formation process through a mix of public and private entities. Table 2 shows the types of entities that participated in GSA formation meetings in our three case studies. Most have direct or indirect interests in agriculture. Local irrigation, reclamation and water districts, and some mutual water companies represent landowners who have access to surface water but often rely in part upon groundwater. Private pumpers are landowners who are not part of a district, and usually rely solely upon groundwater for irrigation, domestic use, or both. Municipalities deliver water for domestic use, but many residents of these cities have ties to agriculture. Agricultural interests were also represented through nonprofit associations, particularly by the Farm Bureau in each county.

\section{Agricultural interests, concerns}

GSA formation represents a significant change for many agricultural users, who in most of California have historically faced few constraints in exercising their overlying rights to pump groundwater. Although SGMA explicitly states that it does not alter property rights, it grants substantial authority to GSAs, including to establish fees, limit extractions and require metering in some instances. In our case studies, local agencies and private pumpers who participated in GSA formation expressed a strong preference to establish GSAs rather than to allow the state to intervene. However, many were concerned about the prospect of larger-scale public agencies such as counties

TABLE 2. Local entities with groundwater interests involved in GSA formation in the three basins

\begin{tabular}{|c|c|c|c|}
\hline & Yolo & Colusa & $\begin{array}{l}\text { Eastern San } \\
\text { Joaquin }\end{array}$ \\
\hline \multicolumn{4}{|l|}{ Local agencies (GSA-eligible) } \\
\hline Water districts & $\checkmark$ & $\checkmark$ & $\boldsymbol{v}$ \\
\hline Irrigation districts & $\checkmark$ & $\checkmark$ & $\boldsymbol{v}$ \\
\hline Reclamation districts & $\checkmark$ & $\checkmark$ & $\boldsymbol{v}$ \\
\hline Cities & $\checkmark$ & $\checkmark$ & $\checkmark$ \\
\hline Counties & $\checkmark$ & $\checkmark$ & $\checkmark$ \\
\hline Community service districts & $\checkmark$ & $\boldsymbol{v}$ & $\boldsymbol{v}$ \\
\hline Drainage districts & $\checkmark$ & $\boldsymbol{v}$ & \\
\hline Levee districts & & $\checkmark$ & \\
\hline Resource conservation districts & $\checkmark$ & $\checkmark$ & \\
\hline Water management-related JPAs & $\checkmark$ & & $\checkmark$ \\
\hline Private water companies & $\boldsymbol{v}$ & $\checkmark$ & $\checkmark$ \\
\hline Landowners/private pumpers & $\checkmark$ & $\checkmark$ & \\
\hline County farm bureau & $\checkmark$ & $\checkmark$ & $\boldsymbol{v}$ \\
\hline Nonprofit water user associations & $\checkmark$ & & \\
\hline $\begin{array}{l}\text { Environmental or other nongovernmental } \\
\text { agencies }\end{array}$ & & $\boldsymbol{V}$ & $\boldsymbol{V}$ \\
\hline Tribes & $\boldsymbol{v}$ & & \\
\hline
\end{tabular}


establishing GSAs, because of the potentially limited familiarity with local water conditions and agricultural needs.

Local water districts and private pumpers had distinct interests and options with respect to their participation in GSA formation. In our case studies - as is true across much of the state - most local irrigation, water and reclamation districts have access to surface water, which provides an alternative water source to groundwater and can be used for direct or in-lieu groundwater recharge. During the GSA formation processes that we observed, many of these districts were concerned about retaining control of surface water deliveries and receiving credit for groundwater recharge in the basinwide water budget that must be included in GSPs. Some sought to protect their interests by forming their own GSAs, as local agencies with water management responsibilities have the right to do under SGMA.

In the Colusa basin, as many as 15 GSA notices were submitted to DWR. Once Glenn and Colusa counties began to convene discussions toward collaboratively forming multi-agency GSAs, districts agreed to participate but developed a set of "districts' principles" to convey their common interests. A few mutual water companies shared interests similar to those of the local districts and participated in developing these principles (under SGMA, water companies cannot form their own GSAs but can be invited by public agencies to be a member of a multi-agency GSA.)

In contrast to the districts' situation, most private pumpers in our case study basins are entirely reliant upon groundwater for irrigation and domestic purposes and have invested significant personal funds in their well systems. In addition, their areas have often experienced the most significant declines in groundwater levels and require more substantial management actions under SGMA.

In these areas - often called "white areas" because they are not covered by other local districts - SGMA presumes that the county will serve as the GSA. In our case studies, many private pumpers did not believe that their county would adequately represent their interests; they were particularly concerned about the potential

TABLE 3. Types of GSAs declared as of June 30, 3017

\begin{tabular}{|c|l|l|}
\hline GSA type & $\begin{array}{l}\text { No. of GSAs } \\
\text { declared }\end{array}$ & $\begin{array}{l}\text { Percentage of } \\
\text { total GSAs }\end{array}$ \\
\hline $\begin{array}{c}\text { Single-agency GSAs } \\
\text { Agencies managing water for agriculture }\end{array}$ & 177 & $70 \%$ \\
\hline $\begin{array}{l}\text { Other agencies } \\
\text { Multi-agency GSAs (JPAs and MOAs) }\end{array}$ & 89 & $35 \%$ \\
\hline $\begin{array}{l}\text { Member(s) of board or advisory committee represent } \\
\text { agricultural interests }\end{array}$ & 61 & $35 \%$ \\
\hline $\begin{array}{l}\text { No specific agricultural representation } \\
\text { Total GSAs declared }\end{array}$ & 15 & $30 \%$ \\
\hline
\end{tabular}

Source: GSA formation notices posted in DWR's SGMA portal (DWR 2017). See technical appendix. fees and pumping restrictions that could be imposed. They sought to establish avenues to represent their interests in the GSA formation process, and ultimately in GSA governance. Their ability to do this rested upon the widely recognized legitimacy of their interests, leading the convening entities to take steps toward meaningfully including the voices of private pumpers.

In Yolo and Eastern San Joaquin basins, private pumpers looked to their county Farm Bureaus to represent their interests in the GSA formation process. In the Yolo basin, the Water Resources Association (WRA, which is composed of irrigation districts, cities and the county) has for several decades been a trusted forum for discussion of the county's water management issues, even more so than the county itself. Aware of the Farm Bureau's strong relationships with individual landowners, the WRA invited the Farm Bureau to coconvene the GSA formation process. Their high level of credibility among agricultural stakeholders resulted in those stakeholders being included in the process of GSA formation. In particular, the Farm Bureau conducted outreach that resulted in the participation of hundreds of private pumpers in public forums about GSA formation.

In the Colusa basin, private pumper advisory committees were created by each of the two counties (Colusa and Glenn). They were composed of private pumper representatives who attended GSA formation meetings and provided concrete proposals for how the GSA could be structured to ensure their interests were represented.

\section{Multiple GSAs per basin}

Numerous water districts in our case studies initially decided to form their own GSAs to retain control over surface and groundwater management activities within their jurisdictions. In the Yolo and Colusa basins, as GSA discussions progressed, many decided to withdraw their notices and join with others to form multi-agency GSAs. However, in the Eastern San Joaquin basin, only a few multi-agency GSAs have formed. Most local agencies have remained single-agency GSAs, resulting in 17 separate GSAs within the basin.

Single agency GSAs are also most common statewide. Agencies may still revise their GSA arrangements but as of the SGMA June 30, 2017, deadline 253 agencies had formed GSAs. The vast majority (70\%) are single agencies. Half are involved in managing water for agriculture (e.g., irrigation or reclamation districts). Agricultural interests also appear to be well represented in the governance structures of multi-agency GSAs (see table 3).

As of June 30, 2017, one or more GSAs had been declared in 113 of the high- and medium-priority basins (GSA formation was not required in some basins that were covered by adjudications or alternative plans). Of these basins, 50 (44\%) have a single GSA covering the entire basin; 29 of those 50 GSAs are multi-agency 
GSAs. The remaining 63 basins are covered by between two and 22 GSAs, or coverage is shared between at least one GSA and an adjudicated area. As figure 2 illustrates, nearly all of the basins in the Central Valley are covered by multiple GSAs. A number of these basins have been designated by the state as "critically

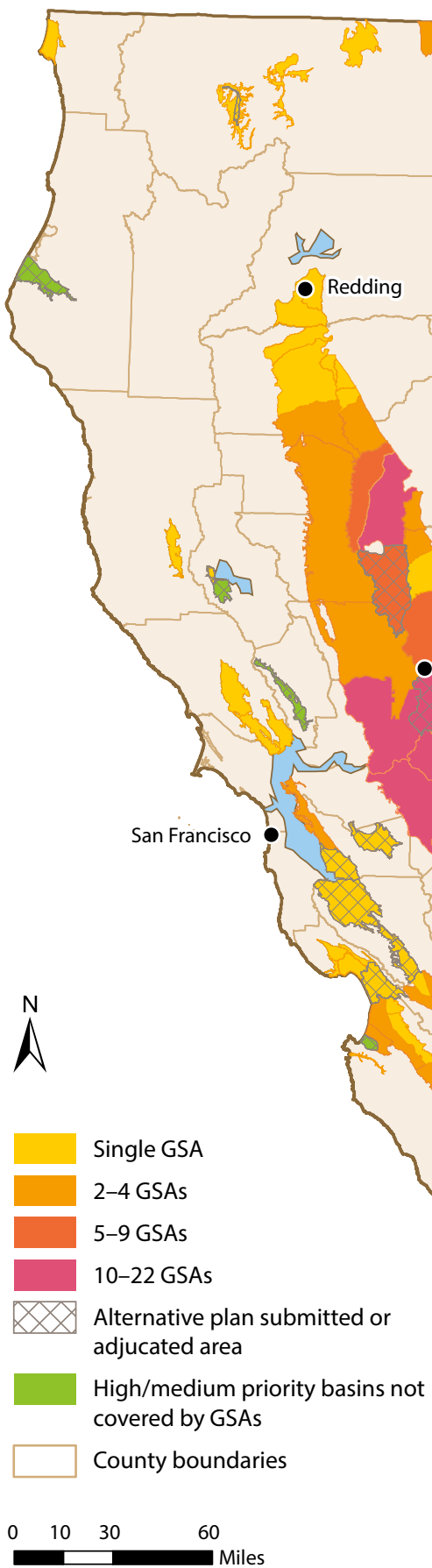

FIG. 2. Number of GSAs formed in high- and medium-priority basins as of June 30,2017 . Basins categorized as low- or very low-priority ${ }^{\circ}$ basins, where GSA formation is not required, are not shown on this map. GSA formation is also not required in high- and medium-priority basins that are covered by adjudications or alternative plans (hatched areas). See technical appendix for further details.

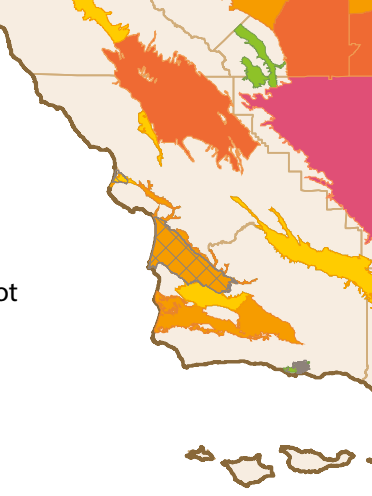

limited, particularly in the large agricultural basins of the Central Valley. However, our cases indicated that there had been significant collaboration in at least some of the basins with multiple GSAs.

In the Yolo and Colusa basins, collaborative, multi-agency GSAs were created, reducing the number of GSAs to two per basin. (The Yolo Subbasin Groundwater Agency covers the entire basin except 200 acres that fall within a reclamation district, which plans to work with the agency on a single GSP.) In the Eastern San Joaquin basin, the 17 GSAs have developed a relatively strong collaborative governance structure at the basin scale. In all three basins, multilevel governance arrangements have emerged that allow local agencies to retain some autonomy, and for private pumpers and other interests to have a voice in decisionmaking. In addition to being reflected in academic literature (Newig and Fritsch 2009), this multilevel approach has been articulated in practical terms as the "local implementing agency" (LIA) model for GSA formation (Ceppos 2016).

Figure 3 illustrates the multilevel governance arrangements that have emerged in our three cases. While the structure and number of GSAs differ, in each basin decision-making and participation are distributed across three levels - basinwide, multi-agency and individual agency - and a distinct set of activities is associated with each.

\section{Basinwide level: GSP development}

In all three cases, basin-scale decision-making focuses on coordination of GSP development, including securing grant funds, hiring consultants, data management and monitoring.

These basinwide structures emerged in large part to share costs and to ensure compliance with SGMA's coordination requirements. In Yolo, the decisionmaking body at the basin scale is the 
Yolo

Basinwide level
Coordination activities for GSP
development

Multi-agency level

Planning for management actions
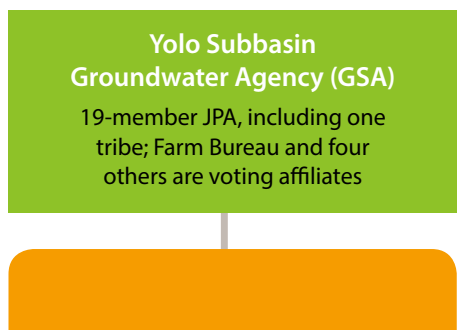

Five management areas

2-9 agencies each, with advisory committees and public input (anticipated)

Individual agency level

Responsibility for GSP

implementation and setting fees

Colusa

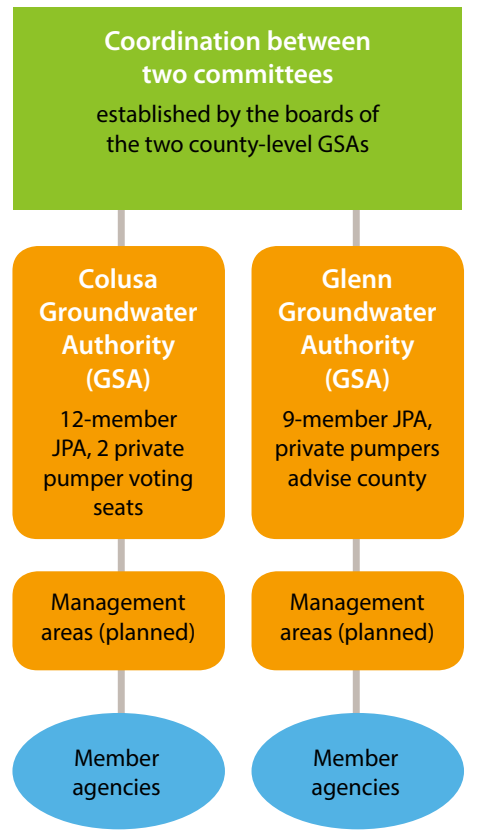

Eastern San Joaquin

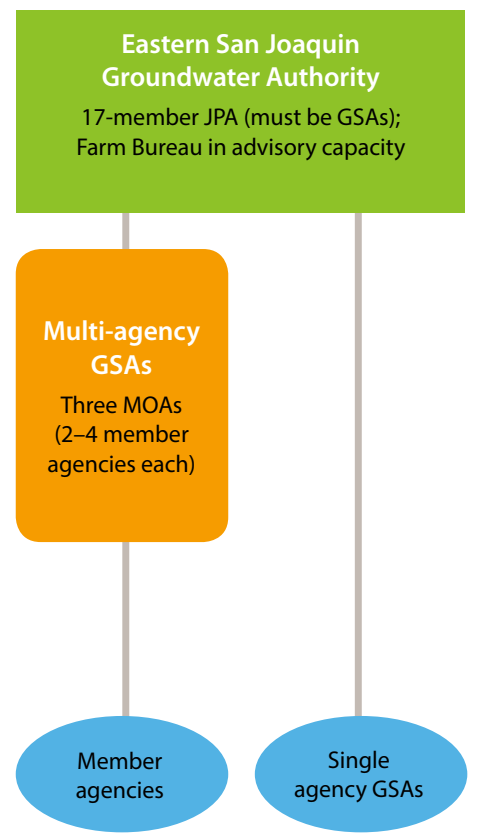

FIG. 3. In each case study, decision-making was distributed across at least three levels. At the basin level, the focus is on coordination and GSP development, while planning for most management actions will occur at the multi-agency level. In keeping with concerns about autonomy, decisions about plan implementation and fees will be undertaken by individual agencies.

GSA; in Eastern San Joaquin, it is a JPA composed of all 17 GSAs. In the Colusa basin, basinwide governance structures are still evolving, but, so far, subcommittees of the boards of the two county-level GSAs are working together on aspects of planning and grant proposal development.

\section{In all three basins, multilevel}

governance arrangements have emerged that allow local agencies to retain some autonomy, and for private pumpers and other interests to have a voice in decision-making.

The restriction of decision-making powers at the basin level was a frequent topic of discussion in GSA formation meetings. As district board member in Yolo County, "I don't want a city telling us when to articulated by an irrigation turn our water on." During several GSA formation meetings, those involved

in convening the process repeatedly acknowledged this concern and emphasized the need to structure the GSA so that as much authority as possible was delegated to local agencies. The JPA establishing the Yolo Subbasin Groundwater Agency reflected this, stating that "the Agency will serve a coordinating and administrative role" without limiting a member's "rights or authority over its own water supply matters," although the GSA retains the right to intervene if sustainability criteria are not being met (Section 8.1, p. 13).

In the Eastern San Joaquin basin, significant portions of several meetings were focused on ensuring that the basinwide JPA, which holds the common powers of its member GSAs, would not usurp the authority of local agencies. The final JPA text restricted the basinwide JPA from undertaking activities "including, without limitation, the restriction or regulation of groundwater extractions," within the service areas of members without their consent (Section 3.6, p. 5).

In the basin-scale governance structures in the Yolo and Eastern San Joaquin basins, private pumper interests are represented by the Farm Bureau. In the Yolo basin, the Farm Bureau serves as one of five affiliated parties who hold voting seats on the GSA board. (Other affiliates include an environmental representative, two mutual water companies and a university.) In the Eastern San Joaquin basin, the Farm Bureau does not have a voting seat but will serve in an advisory capacity to the basinwide JPA, since membership is restricted to GSAs. This arrangement builds upon the Farm Bureau's long history of working with most of the local agencies involved and its experience serving in a nonvoting advisory role to a previous JPA responsible for groundwater management.

\section{Multi-agency level: management actions} Planning for the management actions needed to reach a basin's sustainability goals is largely being conducted by multiple agencies at a scale smaller than a basin (referred to here as the "multi-agency level"). In the Yolo basin, five management areas have been defined within the Yolo Subbasin Groundwater Agency, roughly following groundwater conditions and usage patterns: $\mathrm{Ca}$ pay Valley, North Yolo, Central Yolo, Yolo Zamora, and South Yolo. The specifics of how members and affiliated parties will work together within each management 
area have not yet been spelled out, but advisory committees and opportunities for public involvement are anticipated.

In the Colusa basin, planning for management actions will be undertaken by the two multi-agency GSAs, which have formed along county lines with each covering approximately half of the basin. The two county-level GSAs also anticipate forming management areas, adding yet another governance level.

Although much of the Eastern San Joaquin basin is covered by single-agency GSAs, three multi-agency GSAs have formed in certain subareas of the basin.

For example, the portion of the basin that falls outside of San Joaquin County is being managed by a multiagency GSA composed of two county governments and two water districts.

Private pumpers are involved at the multi-agency level in several ways. In the Colusa County portion of the Colusa basin, there are two voting seats for private pumpers on the board of this multi-agency GSA, both of whom are representatives from the county's Groundwater Commission. In the Glenn County portion of this basin, private pumpers do not sit directly on the GSA board but instead advise the county - which is a member of the GSA - through the previously established Private Pumpers Advisory Committee. Private pumpers will also likely play a role in the Yolo basin by participating in advisory committees to be established for each management area.
Individual agency level: GSP implementation Individual agencies represent a third level of decisionmaking and action, focused on GSP implementation in our case study basins. The delegation of this authority - particularly as related to groundwater use restrictions and fees - to local agencies was critical to reaching agreement to create larger-scale GSAs. For example, one of the Colusa basin's districts' principles, which set out criteria for the districts joining a multi-agency GSA, required that the GSA's governance structure be guided by "respect for each member's discretion, governmental authority, and expertise and knowledge of its groundwater conditions, demands and concerns," as well as an "avoidance of 'top down' planning and implementation” (Districts' principles presentation, Oct. 11, 2016). The JPAs establishing the GSAs in Yolo and Colusa basins, as well as the basinwide JPA of GSAs in Eastern San Joaquin, contain clauses specifying that fee setting and GSP implementation will primarily be undertaken by member agencies.

As of June 30,2017, the counties in each basin were formally serving as the local agencies representing the interests of private pumpers. However, as described earlier, in all three basins private pumpers have avenues to voice their concerns at the multi-agency or basin levels. In the Yolo basin, private pumpers have expressed a preference to be represented by a water district rather than the county, and efforts are under way by this water district to annex private pumper areas.
The expansion of tree crops in Yolo County, where almond acreage has more than doubled since 2010 , has led to increased demand for groundwater. The extent and distribution of tree crops may affect farmers' interests in participating in a GSA and might shape how management areas are formed.

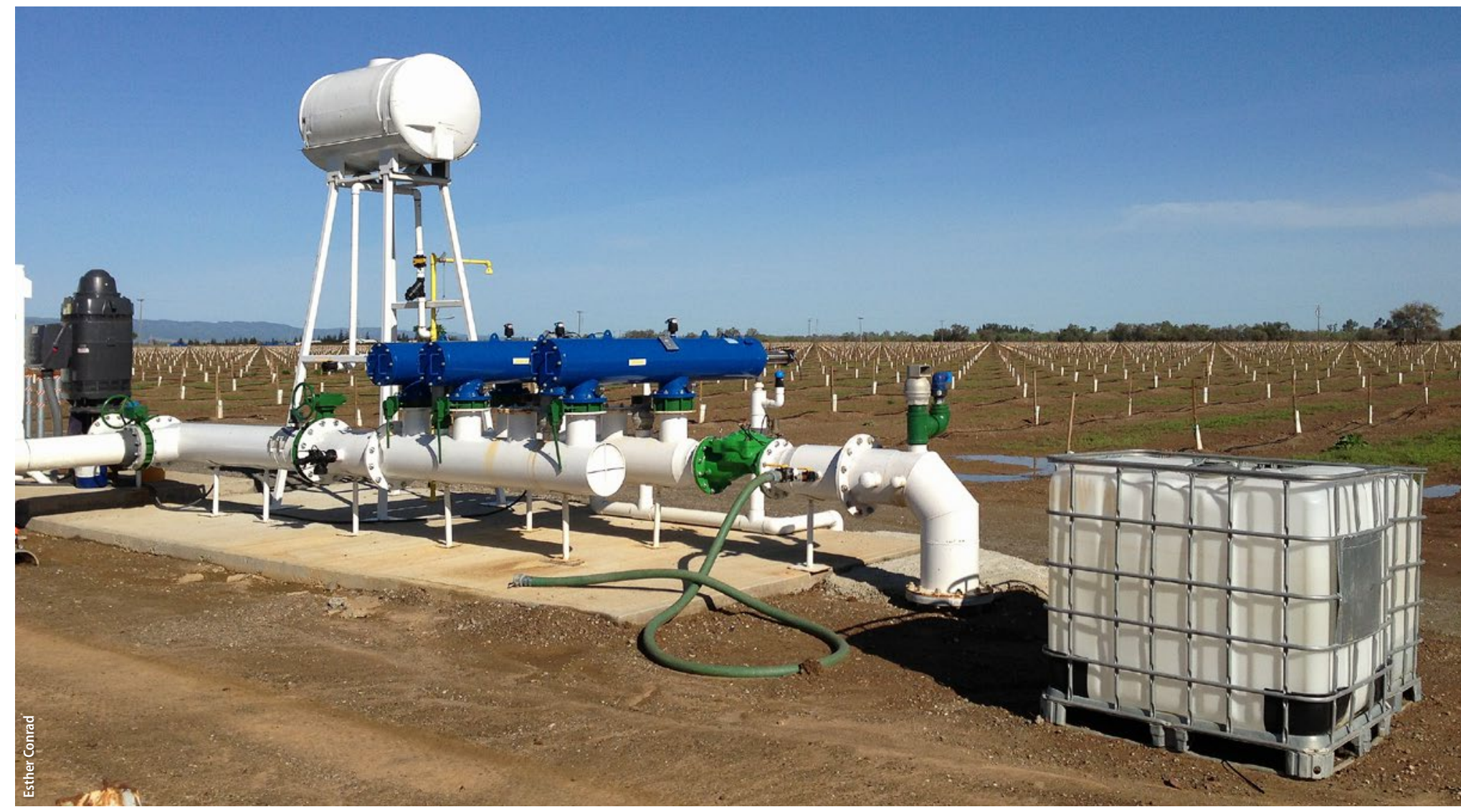




\section{Key Case Study Findings}

\section{Concerns of agricultural stakeholders:}

- Most agricultural stakeholders wanted to preserve some autonomy over decision-making, particularly with regard to setting fees and extraction limits.

- Irrigation, reclamation and other water districts sought to protect their ability to control surface water supplies and to receive credit for groundwater recharge. Under SGMA, these districts had the option to form their own GSAs.

- Private pumpers outside of district boundaries (often called white areas) were concerned about the potential fees and pumping restrictions that a new GSA might impose. Concerned that the county, the default GSA for these areas, would not represent their interests adequately, they sought and gained a voice in decision-making due to the widely recognized legitimacy of their interests.

\section{How these concerns influenced governance:}

- Stakeholders ultimately agreed upon collaborative governance arrangements at the basin scale.

- Concerns about autonomy were accommodated by creating multilevel governance structures in which decision-making is distributed across three levels: basinwide, multi-agency and individual agency.

- Counties represent private pumpers in the GSAs of all three basins, but private pumper representatives and the Farm Bureau have voices in decisionmaking at basinwide and multi-agency levels.

\section{Fair and effective?}

SGMA presents significant challenges and opportunities for collaborative governance, particularly in large agricultural basins where beneficial users are numerous and diverse. The GSA formation process has resulted in the creation of multiple GSAs in many such basins, particularly in the Central Valley. As summarized in the sidebar "Key Case Study Findings", our case studies show how multi-level governance structures have helped in such settings to meet SGMA's requirements for collaborative management at the basin scale while also enabling broad participation and addressing local agency concerns about autonomy. They also illustrate how private pumpers have sought and gained a voice in GSA governance arrangements based upon the widely recognized legitimacy of their interests.

Kiparsky et al. (2016) call for ensuring that GSA governance structures are both fair and effective, and identify criteria for evaluating governance options along these two dimensions. Although they have only just started to function, the governance arrangements in our case studies have the potential to meet some of those criteria. For example, the inclusion of private pumpers into decision-making structures enhances representation and participation, two of the criteria related to fairness. One of the criteria for effectiveness - appropriate scale - is addressed through a multilevel structure that operates at the scale of the basin as well as at the scale of distinct subareas of the basin. Multilevel structures may also help meet the effectiveness criterion of capacity by enabling the GSP development process to draw upon the knowledge and resources of local agencies.

Multilevel structures, however, could also pose some challenges for effectiveness. GSP regulations require that plans identify minimum thresholds for each of the six undesirable results, measurable objectives that will result in sustainable management, and 5-year interim milestones (California Code of Regulations, Title 23, Subarticle 3). The regulations allow for measurable objectives and thresholds to be defined differently in each management area, as long as achieving them together will result in sustainability. The Yolo Subbasin Groundwater Agency is taking steps to implement this approach by developing water budgets at all three decision-making scales (individual agency, multiagency and basinwide). However, since responsibility for implementation has been delegated to the individual agency level, it may prove challenging to ensure that all necessary management actions are undertaken to reach a basinwide sustainability goal. In particular, it may be difficult to encourage local agencies to develop and act upon triggers that provide early warning before thresholds are crossed (Christian-Smith and Abhold 2015). While the Yolo Subbasin Groundwater Agency retains the authority to intervene if sustainability criteria are not being met, such a provision does not exist in the basinwide JPA in the Eastern San Joaquin basin.

Ensuring adequate funding, another criterion for effectiveness identified by Kiparsky et al. (2016), may also be challenging. In our case study basins, responsibility for setting fees is largely allocated to individual agencies. If these agencies prove unwilling or unable to establish new fees when necessary, this could jeopardize timely GSP implementation.

Our case studies do not capture the full range of California's diverse agricultural settings. Each basin's governance arrangements will be influenced by its institutional context, past experiences with collaboration, and even by particular individuals who play significant roles in the process. Differences in agricultural settings may also influence outcomes. For example, in basins with large numbers of small farms, more effort may be needed to find feasible avenues to represent the interests of private pumpers. The extent and distribution of tree crops, which can increase dependence on groundwater, may affect farmers' interests in participating in a GSA and might shape how management areas are formed. Research analyzing a larger number of basins is needed to understand how such factors influence governance arrangements.

While further research is needed to understand factors that influence collaborative governance structures and the effectiveness of multilevel arrangements for SGMA implementation, the experiences of our three case studies may be helpful as GSAs consider how they will work together at a basin scale to prepare one or more GSPs, or if they decide to change their 
governance structures. In particular, our case studies suggest that if the multiple GSAs in basins across the Central Valley have not already done so, they should begin to consider questions of basin-scale governance, including how they will work together to meet SGMA's basinwide coordination requirements, how responsibilities will be shared across individual agency, multiagency and basinwide levels, and how private pumper interests will be considered in each.

Our case studies, as well as experiences in other basins, show that building collaboration requires extensive dialogue, and significant time and commitment on the part of all participants. For example, the Yolo Subbasin Groundwater Agency's GSA notice documents over 175 meetings between May 2014 and June 2017 at which the GSA formation process was discussed. In addition, a preliminary study of eight GSA formation processes under way in late 2016 suggested that two factors - positive prior experience with collaboration and the presence of trusted leadership at the basin scale - were particularly important in supporting collaboration (Conrad et al. 2016). As stakeholders gain more experience working with one another in the coming years, it is possible that some GSAs may decide to consolidate into a single basinwide GSA.

Much more remains to be understood regarding the effectiveness of different governing arrangements in managing groundwater basins sustainably. Studies that compare different GSA governance models, including collaborative and noncollaborative as well as multi- or single-level governance arrangements, would help to inform SGMA implementation, as well as provide much-needed insight into whether and how collaboration works to manage resources at large scales. CA

E. Conrad is Postdoctoral Fellow, Water in the West Program, Woods Institute for the Environment, Stanford University, and Martin Daniel Gould Center for Conflict Resolution, Stanford University Law School; T. Moran is Sustainable Groundwater Program Lead, Water in the West Program, Woods Institute for the Environment, Stanford University; M.E. DuPraw is Managing Senior Mediator and Director of Practice Development, Center for Collaborative Policy, California State University Sacramento; D. Ceppos is Managing Senior Mediator, Associate Director and SGMA Program Manager, Center for Collaborative Policy, California State University Sacramento; J. Martinez is Director, Martin Daniel Gould Center for Conflict Resolution and Senior Lecturer, Stanford University Law School; and W. Blomquist is Professor of political science at Indiana UniversityPurdue University, Indianapolis.

The authors are grateful to Beatrice Gordon for her assistance, and to the Stanford Environmental Ventures Project and the S.D. Bechtel, Jr. Foundation for funding this research.

California Agriculture thanks Guest Associate Editor Meredith Niles for her work on this article.

\section{References}

Ansell C, Gash A. 2008. Collaborative governance in theory and practice. J Publ Adm Res Theor 18:543-71.

Ansell C, Torfing J. 2015. How does collaborative governance scale? Policy Polit 43:315-29.

Blomquist W. 1992. Dividing the Waters: Governing Groundwater in Southern California. San Francisco: ICS Press. $415 \mathrm{p}$.

California State Legislature. 2014. Sustainable Groundwater Management Act (and related statutory provisions from SB $1168, A B$ 1739, and SB 1319). Sacramento, CA. http://groundwater.ca.gov/docs/2014\%20 Sustainable\%20Groundwater\%20Management\%20Legislation\%20with\%202015\%20 amends\%201-15-2016.pdf [CDFA] California Department of Food and Agriculture. 2016 California Agricultural Statistics Review 2015-16. Sacramento, CA. 124 p. www.cdfa.ca.gov/sta tistics/PDFs/2016Report.pdf
Ceppos D. 2016. Local Implementing Agencies: A Localized Governance Alternative for the Sustainable Groundwater Management Act. Sacramento: Center for Collaborative Policy, California State University, Sacramento. www.csus.edu/ ccp/documents/publications/ lia_white_paper_final.pdf Christian-Smith J, Abhold K. 2015. Measuring What Matters: Setting Measurable Objectives to Achieve Sustainable Groundwater Management in California. Union of Concerned Scientists, Oakland, CA. 37 p. www.ucsusa.org/measuring whatmatters

Conrad E, Martinez J, Moran T, et al. 2016. To Consolidate or Coordinate? Status of the Formation of Groundwater Sustainability Agencies in California. Water in the West Program, Stanford University, CA. 44 p. http://waterinthewest.stanford.edu/sites/ default/files/GSA-FormationReport_1.pdf

DuPraw ME. 2014. Illuminating Capacity-Building Strategies for Landscape-Scale Collaborative Forest Management Through Constructivist Grounded Theory. Dissertation, Graduate School of Humanities and Social Sciences, Nova Southeastern University, Ft. Lauderdale.
[DWR] California Department of Water Resources. 2017. SGMA Portal. http://sgma.water ca.gov/portal/

DWR. 2016. Final 2016 Bulletin 118 Groundwater Basin Boundaries. GIS shapefiles. Sacramento, CA. http://water ca.gov/groundwater/sgm/basin_boundaries.cfm

DWR. 2015. California's Groundwater, Update 2013. Sacramento, CA. 90 p. www. water.ca.gov/waterplan/topics/ groundwater/index.cfm

DWR. 2014. California Statewide Groundwater Elevation Monitoring (CASGEM) and Groundwater Sustainability Basin Prioritization. Sacramento, CA. www.water.ca.gov/groundwater/casgem/pdfs/lists/ PubRel_BasinRank_by_HR_518-15.pdf

Emerson K, Nabatchi T, Balogh S. 2012. An integrative framework for collaborative governance. $J$ Publ Adm Res Theor 22:1-29. Hughes S, Pincetl S. 2014. Evaluating collaborative institutions in context: The case of regional water management in southern California. Environ Plann C 32:20-38.
Huitema D, Mostert E, Egas W, et al. 2009. Adaptive water governance: Assessing the institutional prescriptions of adaptive (co-)management from a governance perspective and defining a research agenda. Ecol Soc 14:1.

Innes JE, Booher DE. 2010 Planning with Complexity: An Introduction to Collaborative Rationality for Public Policy. New York, NY: Routledge. 256 p.

Kiparsky M, Owen D, Nylen NG, et al. 2016. Designing Effective Groundwater Sustainability Agencies: Criteria for Evaluation of Local Governance Options. Center for Law, Energy and the Environment, UC Berkeley School of Law. 63 p. www.law. berkeley.edu/groundwatergovernance-criteria

Megdal SB, Gerlak AK, Huang L, et al. 2017. Innovative approaches to collaborative groundwater governance in the United States: Case studies from three high-growth regions in the Sun Belt. Environ Manage 59:718-35

Morain D. 2015. Drought transforms Valley, right in our own backyards. Sacramento Bee, October 30.
Nelson R. 2011. Uncommon Innovation: Developments in Groundwater Management Planning in California. Water in the West Working Paper 1 . Stanford University, CA. 38 p. http://waterinthewest.stanford. edu/sites/default/files/UncommonlnnovationMarch_2011.pdf Newig J, Fritsch O. 2009. Environmental governance: Participatory, multi-level — and effective? Environ Policy Gov 19:197-214.

Ostrom E. 1990. Governing the Commons: The Evolution of Institutions for Collective Action. Cambridge: Cambridge University Press. 298 p.

Purdy JM. 2012. A framework for assessing power in collaborative governance processes. Public Admin Rev 72:409-17.

[USDA] United States Department of Agriculture. 2014. 2012 Census of Agriculture: California State and County Data. Vol. 1 , Part 5. Washington, DC. 550 p. www.agcensus.usda.gov/ Publications/2012/Full_Report/ Volume_1,_Chapter_2_County Level/California/cav1.pdf 